\title{
Mucormycosis: An Epidemic Associated with Pandemic- A Systematic Review
}

\section{MIR TABISH SYEED ${ }^{1}$, ISHITA MAMGAIN², DIKSHA SHARMA*1, ISHAN TRISAL²}

Different infections have been presenting danger to mankind every once in a while and in 2019 a serious respiratory illness (COVID-19) reported in Wuhan, Hubei province of China, became a threat to general wellbeing not only in China but all the nations throughout the world. COVID-19 disease which is caused by severe acute respiratory syndrome coronavirus 2 (SARS-CoV-2) is found to be associated with a wide range of opportunistic fungal and bacterial infections. Candidial and aspergillus infections leading to mucormycosis and orbital compartment syndrome have been reported to be the main co-infections in COVID-19 patients, which must be recognized and treated promptly to avoid any morbidity and mortality. Low oxygen environment, acidic medium, high glucose, decreased phagocytic activity and increased ferritin levels in addition to prolonged hospitalization with or without mechanical ventilators are considered as the main risk factors. Thus, the main aim of the article is to briefly survey and discuss about the types, causes, methods to prevent and treatment modalities of main co-morbidity of COVID 19 i.e. mucormycosis.

KEYWORDS: COVID-19, Fungal Infection, Mucormycosis, Steriods

\section{INTRODUCTION}

Coronavirus, an outsized family of viruses, noted to cause diseases which range from simple cold to more severe diseases like severe SARS (2002 - 2004) and MERS (2012) (WHO, 2020). A much recent, Novel coronavirus (COVID-19) caused by similar family of viruses is an infectious disease primarily associated with symptoms ranging from mild to severe lifethreatening conditions particularly pneumonia. ${ }^{1}$ First ever case was recorded in Wuhan city of China during the ending month of 2019 and has been associated with myriad of fungal, bacterial and viral co-infections. While the pathophysiology is still under investigation, new indicative manifestations and complications of the same continue to be identified and described in medical literature. ${ }^{2}$

Since the beginning of this pandemic, a large number of studies have centered on quick diagnosis, advancement, and redirection of new treatment plans. In many cases, it was found that SARS-CoV-2 is something much more than a respiratory disorder. Significant degrees of endogenous substances delivered by this infection are capable of producing changes and disturbances influencing the target tissues. They even go past the hindrances of protection of the innate tissue immunity, reaching the systemic level through hematogenous transmission. ${ }^{3}$ This signalling animates immunity cells associated with constant chronic inflammatory process that can promptly lead to fibrosis of lungs, loss of function, pulmonary degeneration, oxygenation impairment, culminating the delayed hypoxic state, anoxemia and hypoxemia and ultimately leading to death. Patients having metabolic diseases such as diabetes mellitus, autoimmune diseases, cardiopulmonary diseases, or patients undergoing chemotherapy, corticotherapy or radiotherapy have a higher danger of death. ${ }^{4}$

Apart from arrhythmias, thrombo-embolic complications, cardiac injury (acute), and strokes, secondary opportunistic infections including white fungus (candidiasis) and black fungus (mucormycosis) are much prevalent.

\section{MUCORMYCOSIS}

Zycomycosis or Phycomycosis was first described by Paltauf in 1885 and later changed to Mucormycosis by Baker (American pathologist) in 1957 due to severe form of infection caused by Rhizopus. Fungi which belong to the order Mucorales are distributed into six families and all are responsible for cutaneous and deep infections. ${ }^{5}$ Head of the fungal pathogenesis group at the institute for medical research, Julie Djordjevic described it as a "NATURE'S DECAYER". ${ }^{6}$

The Rhizopus Oryzae type is responsible for nearly 
$60 \%$ of mucormycosis cases in humans and $90 \%$ of the Rhino-orbital-cerebral form. It is usually uncommon but can occur as an opportunistic severe fungal infection in people who have altered immune system and affects the sinuses, lungs and brain leading to life threatening conditions in cancer patients, diabetic patients, or people suffering from HIV or AIDS. These pathogens are commonly present in soil along with association with decaying organic matter, such as rotten wood, compost piles, or leaves. It is commonly transmitted through inhalation of these fungal spores. ${ }^{7}$

\section{PATHOGENESIS}

Both mononuclear and polymorphonuclear phagocytes of ordinary hosts kill Mucorales by the creation of metabolites and the cationic peptides defensins. Clinical proof exhibits that these phagocytes are the significant host defense system against mucormycosis. For instance, neutropenic and phagocytic dysfunctional patients are at expanded danger of creating mucormycosis. The capacity of phagocytes to engulf these fungi by their oxidative and nonoxidative components is disabled by hyperglycemia (diabetes mellitus) and acidosis. Furthermore, corticosteroid treatment influences the capacity of broncho alveolar phagocytes to prevent germination of the spores in vitro or after in vivo contamination initiated by intranasal inoculation. The specific components by which ketoacidosis, diabetes, or steroids impede the capacity of these phagocytes stay obscure. ${ }^{5}$

\section{CLINICAL PRESENTATION}

The clinical sign of this disease (mucormycosis) is vascular invasion leading to tissue necrosis and thrombosis. Mucormycosis practically consistently happens in people with defects in host defense mechanism and/or potentially with increased available serum iron, albeit uncommon cases have been accounted for in evidently normal hosts. This disease is determinedly progressive and results in death except if treatment with a careful surgical debridement and antifungal drugs is started instantly. ${ }^{8}$

According to the clinical presentation and the involvement of a specific anatomic site, mucormycosis has been divided into at least six clinical classifications: (1)pulmonary, (2)disseminated, (3)cutaneous, (4)gastrointestinal, (5)rhinocerebral, and (6)miscellaneous (table 1).

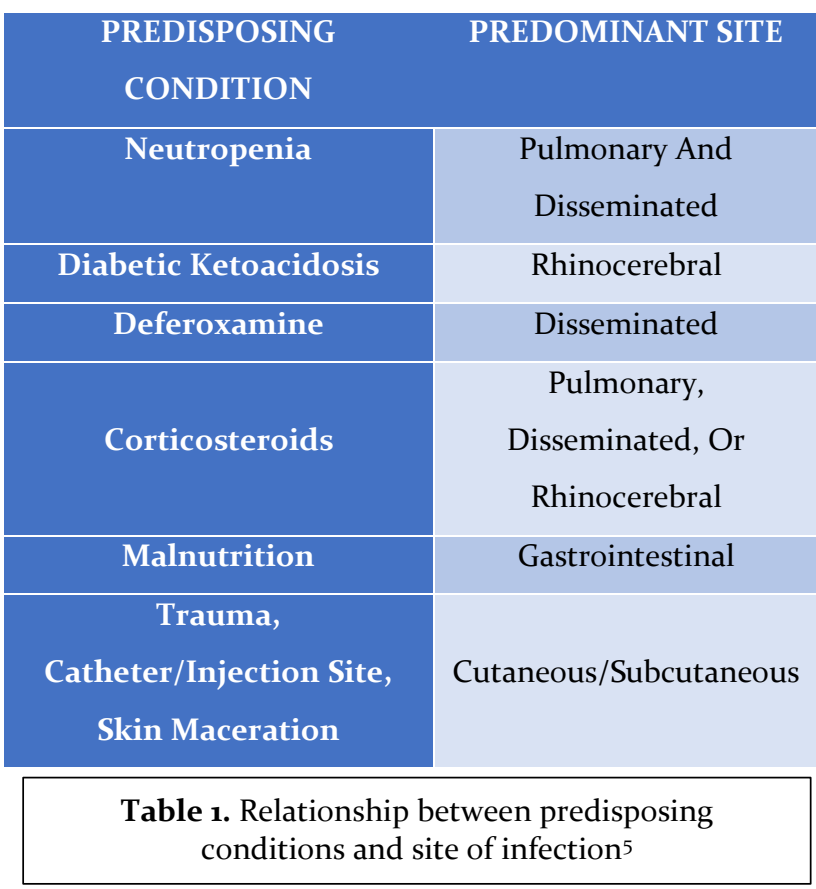

\section{SYMPTOMS}

Sinusitis along with clogging of the nasal tract with blackish or bloody mucus emission from the nose is the main indication of mucormycosis. Blackish discoloration on the bridge of the nose, along with pain on one side of the face, cheekbone and lack of sensation and buldging of the involved area are observed. Abnormal clotting of blood tissue thrombosis, damage or injury to the skin and/or necrosis of the dermal cells are also seen. Impairment of respiratory functions, pain in chest, excessive buildup of fluid in lungs and haemoptysis are also observed. 9

Blood clots with blocked vessels, blindness and nerve damage prove mucormycosis is deadly if not treated. Due to its rare nature, the exact mortality is unknown but an overall estimate is roughly around $45 \%$. The likelihood of patient's death depends on the body part affected. $^{10}$

\section{DIAGNOSIS}

The exact time for the presentation of this disease in covid patient is usually around third week of onset of its symptoms. Physical examination, swab test, followed by tissue biopsy and radiographic imaging (CT or MRI) are used to detect the extent of it.

Specific investigations include 1. Non-contrast 
computed tomography scan of the sinuses particularly paranasal sinuses (NCCT PNS) to detect the bony erosion; 2. High resolution computed tomography chest (HRCT chest) and CT Angiography and 3. MRI of the brain for better delineation of CNS involvement.

Diagnosis includes 1. KOH staining and microscopy, followed by histopathology of the debrided tissues and culture; 2. Matrix-assisted laser desorption/ionizationtime of flight (MALDI-TOF) mass spectrometry if available and 3. Presence of ribbon like aseptate hyphae $(5-15 \mu)$, branching at right angles. ${ }^{11}$

\section{PREVENTION AND TREATMENT}

Ensuring proper oral hygiene, wearing face shields and masks, maintaining hand hygiene, regular changing of masks and avoiding unnecessary visits to crowded and dirty or polluted environments are main prevention goals in preventing any co-morbidity related to covid.

For prevention of mucormycosis, it is important to control hyperglycemia, discontinue any immunomodulating drug and reduce the use of steroids. Maintaining the adequate systemic hydration, normal saline (IV) infusion followed by amphotericin B and anti-fungal therapy for atleast 4-6 weeks is required. In case of diabetic and covid patients, it is very much important to control hyperglycemia and regularly monitor blood glucose levels during and after Covid treatment. Steroid use must be judicious with correct dosage, timing and duration. ${ }^{6}$

The major treatment part includes antifungals but depending upon the severity, surgery is the end treatment. Mucormycosis can cause damage to upper jaw and even eye. Loss of functions including facial aesthetics, chewing, swallowing and loss of self-esteem can lead to the detrimental effect on the patients mental health. Hence management of covid patients with mucormycosis approach involving team of professionals such as microbiologist, internal medicine specialist, ENT specialist, ophthalmologist, dental surgeon (oral and maxillofacial surgeon for reconstruction) and others. ${ }^{2}$

\section{METHOD}

A systematic search of literature was done in the electronic database of SCOPUS, PUBMED, COCHRANE and EMBASE, using keywords SARS CoV2, COVID 19 and MUCORMYCOSIS. Details of articles that reported confirmed and suspected patients with mucormycosis, so far till June 2021 were retrieved. Characteristic of the subjects were analysed on various endpoints and outcomes (table 2).

\section{DISCUSSION}

Though been an extremely rare case (mucormycosis) in healthy individual, severe immunocompromised patients predispose it. Uncontrolled diabetes mellitus with or without diabetic ketoacidosis, organ transplantation, hematological and various other malignancies, corticosteroid therapy, prolonged neutropenia, iron overload, voriconazole prophylaxsis for transplantation patients, AIDS, and malnutrition are main predisposing factors. Nose, sinuses, CNS, orbit, lungs, GIT, skin, joints, jaw bone are the areas involved, though rhino-orbital-cerebral (ROC) form is more common among all. ROC form is frequently observed in association with uncontrolled diabetes and diabetic ketoacidosis, whereas pulmonary involvement is often seen in patients suffering from neutropenia, and hematological malignancies while GIT involvement is seen in malnourished individuals. ${ }^{26}$

Eosinophilic necrosis, thrombosis, and giant cell invasion of the underlying area is the main pathological symptom of mucormycosis. Its gold standard criteria for clinical diagnosis was given by Smith and Krichner in 1950 which included: black and necrotic turbinate, easily misdiagnosed for crusted, dried blood. Blood tinged nasal discharge with facial pain, soft peri-orbital swelling, ptosis and proptosis of the eye with a multiple number of cranial nerve palsies. ${ }^{27}$

Prakash et al. ${ }^{28}$ (2019) and Patel et al. ${ }^{29}$ ( 2020) have found that rhino-orbital-cerebral was the utmost presentation which was followed by pulmonary and cutaneous type in patients with uncontrolled hyperglycaemia. Systematic review by John et al reported 41 cases in people with COVID-19 and diabetes was found in $93 \%$ of the cases and $88 \%$ were on steroid therapy. These findings were consistent with that of Awadesh et al, where they found that 8o\% of the mucormycosis cases were hyperglycemic and $76.3 \%$ received corticosteroids. ${ }^{30}$ No studies are available that compared patients of mucormycosis with/without confounding factors.

\section{LIMITATION}

Various limitations were seemed to be found while conducting this systematic review, using case reports 


\begin{tabular}{|c|c|c|c|c|c|c|c|}
\hline AUTHOR & YEAR & $\begin{array}{l}\text { PLACE OF } \\
\text { REPORT }\end{array}$ & $\mathbf{N}$ & $\begin{array}{c}\text { CO- } \\
\text { MORBIDITIES }\end{array}$ & $\begin{array}{l}\text { CONFIRMED/SU } \\
\text { SPECTED CASES }\end{array}$ & LOCATION & OUTCOME \\
\hline Mehta et al ${ }^{12}$ & Sep,2020 & Mumbai & 1 & Diabetes & Confirmed & Nasal, Orbit & Death \\
\hline Hanley et al'13 & Oct,2020 & UK & 1 & Nil & Confirm, Autopsy & Lung & Death \\
\hline Placik et al14 & Nov,2020 & USA & 1 & Nil & Confirmed & Lung & Death \\
\hline $\begin{array}{c}\text { Monte Junior } \\
\text { et al }{ }^{15}\end{array}$ & $\mathrm{Nov}, 2 \mathrm{O} 2 \mathrm{O}$ & Brazil & 1 & Nil & Confirmed & GIT & Death \\
\hline Zurl et $\mathrm{al}^{16}$ & Jan,2021 & Austria & 2 & Leukemia & Confirmed & Bone & Death \\
\hline Sarkar et al ${ }^{17}$ & Apr,2021 & Puducherry & 10 & Diabetes & $\begin{array}{l}\text { Confirmed:6 } \\
\text { Suspected:4 }\end{array}$ & $\begin{array}{c}\text { Nasal, Orbit, } \\
\text { CNS }\end{array}$ & $\begin{array}{c}\text { Death:4 } \\
\text { Improved:2 } \\
\text { Unchanged:4 }\end{array}$ \\
\hline $\begin{array}{c}\text { Sharma et } \\
\text { al }^{18}\end{array}$ & Apr 2021 & Jaipur & 23 & Diabetes & Confirmed & $\begin{array}{c}\text { Nasal, Orbit, } \\
\text { CNS }\end{array}$ & $\begin{array}{c}\text { Death: o } \\
\text { Lost To Follow Up:2 } \\
\text { Alive: } 21\end{array}$ \\
\hline Veisi et al $^{19}$ & Apr, 2021 & Iran & 2 & Diabetes & Confirmed & $\begin{array}{c}\text { Nasal, Orbit, } \\
\text { CNS }\end{array}$ & $\begin{array}{c}\text { Death:1 } \\
\text { Recovered:1 }\end{array}$ \\
\hline Garg et $\mathrm{al}^{20}$ & May,2021 & Chandigarh & 1 & Diabetes & Confirmed & Lung & Improved \\
\hline Mishra et al ${ }^{21}$ & May,2021 & Bangalore & 10 & Diabetes & Confirmed & $\begin{array}{c}\text { Nasal, Orbit, } \\
\text { Bone }\end{array}$ & $\begin{array}{c}\text { Death:4 } \\
\text { Improved:2 } \\
\text { Unchanged:4 }\end{array}$ \\
\hline Satish et al $^{22}$ & May,2021 & Bangalore & 11 & $\begin{array}{l}\text { Diabete:10 } \\
\text { Leukemia:1 }\end{array}$ & Confirmed & Nasal, Orbit & $\begin{array}{c}\text { Death:2 } \\
\text { No Medical Advice:5 } \\
\text { Improved:4 }\end{array}$ \\
\hline $\begin{array}{l}\text { Johnson et } \\
\qquad \mathrm{al}^{23}\end{array}$ & Jun,2021 & USA & 1 & Diabetes & Confirmed & Lung & Improved \\
\hline Sen et $\mathrm{al}^{24}$ & 2021 & Mumbai & 6 & Diabetes & $\begin{array}{l}\text { Confirmed:5 } \\
\text { Suspected:1 }\end{array}$ & $\begin{array}{c}\text { Nasal, Orbit, } \\
\text { CNS }\end{array}$ & Improved \\
\hline $\begin{array}{c}\text { Wetherman } \\
\text { et } \mathrm{al}^{2}\end{array}$ & 2021 & USA & 1 & Nil & Confirmed & Nasal, Orbit & Improved \\
\hline Sargin et $\mathrm{al}^{25}$ & 2021 & Turkey & 1 & Diabetes & Confirmed & $\begin{array}{c}\text { Nasal, Orbit, } \\
\text { CNS }\end{array}$ & Death \\
\hline
\end{tabular}

Table 2. Characteristic of the subjects reported by various authors analysed on the basis of various endpoints and outcomes

and series which are subjected to publication biases with considerable diversity of the reported cases. The active and recovered SARS $\mathrm{CoV}-2$ cases and its correlation to the onset of mucormycosis is difficult due to the less sensitivity of confirmatory reverse transcriptase polymerase chain reaction. Lack of denominator value, does not allow the real estimation of the incidence of mucormycosis.

\section{CONCLUSION}

COVID-19 is found to be associated with significant incidence of opportunistic bacterial and fungal infections due to immune dysfunction. Additional due to steroid therapy, broad spectrum antibiotics, monoclonal antibodies lead to exaggeration of preexisting fungal diseases. While still, there is no major outbreak, physicians should be aware of the possibility 
of invasive opportunistic infections in patients with SARS CoV-2 and pre-existing risk factors. Use of therapeutic agents should be monitored to achieve the effect at the minimal dose and for the momentary duration for maximum efficacy. Thus, it becomes very much essential to make the judicious use of drugs and reducing major outbreak with decreased mortality.

\section{REFERENCES}

1. Mehta S, Pandey A. Rhino-orbital mucormycosis associated with COVID-19. Cureus 2020;12(9):e10726. https://doi.org/10.7759/cureus.10726

2. Werthman-Ehrenreich A. Mucormycosis with orbital compartment syndrome in a patient with COVID-19. The American Journal of Emergency Medicine 2021;42:264-e5.

https://doi.org/10.1016/j.ajem.2020.09.032

3. Jin Y, Ji W, Yang H, Chen S, Zhang W, Duan G. Endothelial activation and dysfunction in Covid-19: From basic mechanisms to potential therapeutic approaches. Signal Transduct Target Ther. 2020;5(1):293. https://doi.org/10.1038/s41392-02000454-7

4. Grosse C, Grosse A, Salzer HJF, Dunser MW, Motz R, Langer R. Analysis of cardiopulmonary findings in Covid-19 fatalities: High incidence of pulmonary artery thrombi and acute suppurative bronchopneumonia. Cardiovasc. Pathol. 2020, 49, 107263.

5. Spellberg B, Edwards Jr J, Ibrahim A. Novel perspectives on mucormycosis: pathophysiology, presentation, and management. Clinical Microbiology Reviews. 2005;18(3):556-69.

6. Kameshwaran S, Sriram N, Darla R, Manimekalai P, Dhanalakshmi M. Symptoms and treatment strategy of black fungus in Covid-19 patients. Int $\mathrm{J}$ of Pharmacology and Clin Research 2021; 5(2):24-7.

7. Sugar AM. In: Mandell GL, Bennett JE, Dolin R, editors. Mandell, Douglas, and Bennett's principles and practice of infectious diseases. Fifth ed. New York, USA: Churchill Livingstone; 2000.

8. Larsen K, von Buchwald C, Ellefsen B, Francis D. Unexpected expansive paranasal sinus mucormycosis. ORL J Otorhinolaryngol Relat Spec. 2003;65(1):57-6o. https://doi.org/10.1159/oooo68657

9. Times of India. Mucormycosis Symptoms: How to identify signs and symptoms of mucormycosis, aka black fungus infection in COVID cases. (Online Article). Available from: https://timesofindia.indiatimes.com/life-style/healthfitness/health-news/coronavirus-black-fungus-how-toidentify-signsand-symptoms-of-mucormycosis-akablack-fungus-infection-in-covid- cases/photostory/82567426.cms [Last Accessed on $15^{\text {th }}$ May, 2021]

10. Sreenivas S. Mucormycosis: What to Know. (Online Article). Available from: https://www.webmd.com/lung/mucormycosis-blackfungus-infection. [Last Accessed on 15th May, 2021] 11. Alekseyev K, Didenko L, Chaudhry B. Rhinocerebral mucormycosis and COVID-19 pneumonia. Journal of Medical Cases 2021;12(3):85. https://doi.org/10.14740/jmc3637

12. Mehta S, Pandey A. Rhino-orbital mucormycosis associated with COVID-19. Cureus 2020;12(9). e10726. https://doi.org/10.7759/cureus.10726

13. Hanley B, Naresh KN, Roufosse C, et al. Histopathological findings and viral tropism in UK patients with severe fatal COVID-19: a post-mortem study. Lancet Microbe 2020;1(6):e245e53. https://doi.org/10.1016/S2666-5247(20)30115-4

14. Placik DA, Taylor WL, Wnuk NM. Bronchopleural fistula development in the setting of novel therapies for acute respiratory distress syndrome in SARSCoV- 2 pneumonia. Radiol Case Rep. 2020;15(11):2378e81. https://doi.org/10.1016/j.radcr.2020.09.026

15. Monte Junior ESD, Santos MELD, Ribeiro IB, et al. Rare and fatal gastrointestinal mucormycosis (zygomycosis) in a COVID-19 patient: a case report. Clin Endosc 2020;53(6):746-9. https://doi.org/10.5946/ce.2020.180.

16. Zurl C, Hoenigl M, Schulz E, et al. Autopsy proven pulmonary mucormycosis due to Rhizopus microsporus in a critically ill COVID-19 patient with underlying hematological malignancy. J Fungi (Basel). 2021;7(2):88. https://doi.org/10.339o/jof7020088.

17. Sarkar S, Gokhale T, Choudhury SS, Deb AK. COVID-19 and orbital mucormycosis. Indian J Ophthalmol. 2021;69(4):1002-4. https://doi.org/10.4103/ijo.IJO_3763_20

18. Sharma S, Grover M, Bhargava S, Samdani S, Kataria T. Post coronavirus disease mucormycosis: a deadly addition to the pandemic spectrum. J Laryngol Otol. 2021;135(4):442-7.

https://doi.org/10.1017/Soo22215121000992

19. Veisi A, Bagheri A, Eshaghi M, Rikhtehgar MH, Rezaei Kanavi M, Farjad R. Rhino-orbital mucormycosis during steroid therapy in COVID-19 patients: a case report. Eur J Ophthalmol. 2021: 11206721211009450.

https://doi.org/10.1177/11206721211009450

20. Garg D, Muthu V, Sehgal IS, Ramachandran R, et al. Coronavirus disease (Covid-19) associated mucormycosis (CAM): case report and systematic 
review of literature. Mycopathologia 2021;186(2):28998. https://doi.org/10.1007/s11046-021-00528-2

21. Mishra N, Mutya VSS, Thomas A, et al. A case series of invasive mucormycosis in patients with COVID-19 infection. Int J Otorhinolaryngol Head Neck Surg. 2021;7(5):867-70. https://doi.org/10.18203/issn.24545929.ijohns20211583

22. Satish D, Joy D, Ross A, Balasubramanya. Mucormycosis coinfection associated with global COVID-19: a case series from India. Int J Otorhinolaryngol Head Neck Surg. 2021;7(5):815-20. https://doi.org/10.18203/issn.2454-

5929.ijohns20211574

23. Johnson AK, Ghazarian Z, Cendrowski KD, Persichino JG. Pulmonary aspergillosis and mucormycosis in a patient with COVID-19. Med Mycol Case Rep. 2021;32:64-7. https://doi.org/10.1016/j.mmcr.2021.03.006

24. Sen M, Lahane S, Lahane TP, et al. Mucor in a viral land: a tale of two pathogens. Indian J Ophthalmol 2021;69:244-52.

https://doi.org/10.4103/ijo.IJO_3774_2o.
25. Sargin F, Akbulut M, Karaduman S, Sungurtekin H. Severe rhinocerebral mucormycosis case developed after COVID 19. J Bacteriol Parasitol. 2021;12(1):386.

26. Sugar AM. Mucormycosis. Clin Infect Dis. 1992;14:S126-9.

https://doi.org/10.1093/clinids/14.supplement_1.s126 27. Smith HW, Kirchner JA. Cerebral mucor-mycosis: a report of 3 cases. Arch Otolaryngol. 1950;68:715-26. https://doi.org/10.1001/archotol.1958.00730020739010 28. Prakash H, Ghosh AK, Rudramurthy SM, Singh P, Xess I, Savio J, et al. A prospective multicenter study on mucormycosis in India: epidemiology, diagnosis, and treatment. Med Mycol. 2019;57:395-402. https://doi.org/10.1093/mmy/myyo6o

29. Patel A, Kaur H, Xess I, et al. A multicentre observational study on the epidemiology, risk factors, management and outcomes of mucormycosis in India. Clin Microbiol Infect. 2020;26(7). 944.e9-944.e15. https://doi.org/10.1016/j.cmi.2019.11.021

30. Singh AK, Singh R, Joshi SR, Misra A. Mucormycosis in COVID-19: a systematic review of cases reported worldwide and in India. Diabetes \& Metabolic Syndrome: Clinical Research \& Reviews. 2021;15(4):102146.

https://dx.doi.org/10.1016\%2Fj.dsx.2021.05.019 